\title{
IMPÉRIO E GOVERNO REPRESENTATIVO: uma releitura
}

\author{
M iriam D olhnik off
}

O processo de construção do Estado nacional no Brasil, no decorrer do século XIX, envolveu uma série de fatores complexos, incluindo perspectivas diferentes sobrequal deveria ser seu perfil institucional. Nesse contexto, a opção pela monarquia constitucional foi a derrota darepública, mas sem que a elite política abdicasse, pelo menos em seu discurso, da adoção deum governo representativo. O modelo demonarquia vinha da Europa, onde, a partir da experiênciainglesa eda revolução francesa, estava associado à representação política dos diversos setores da sociedadeatravés do parlamento. Contudo, a presença da escravidão, a fraudeea violência nas el eições, o Poder Moderador, com sua atribuição dedissolver a Câ mara dos Deputados, levaram os historiadores a desconfiarem da afirmação dos políticos oitocentistas dequeestavam construindo umgoverno representativo.

* Doutora em História Econômica pela USP. Professora do Departamento de História da USP e pesquisador do Centro Brasileiro de Análise e Planejamento-CEBRAP. Cidade Universitária - Butantã - Sao Paulo, SP - Brasil. miriamdk@uol.com.br
O objetivo destetexto é recol ocar essa discussão em outros termos. Esta pesquisa deriva de trabal ho anterior no qual foi anal isadaa organização institucional do Estado brasileiro no século XIX, demodo a averiguar a forma deinserção das elites provinciais no jogo político. Utilizando o arcabouço conceitual daciênciapolíticaeumavasta pesquisa documental, de modo a examinar não apenas o discurso dos políticos, mas também a dinâmicadesseEstado, concluiu-sequepredominou, no séculoXIX, umarranjo detipo federativo. O quesignificava, entreoutras coisas, a capacidade de as elites provinciais participarem do jogo político nacional através da sua representação na Câmara dos Deputados (Dolhnikoff, 2004). Essa conclusão colocou a necessidade de repensar o papel da Câmara na condução do Estado e considerar a hipótese de que ela efetivamente foi um espaço denegociação de conflitos intra-elitee de formulação de políticas nacionais. O que, por sua vez, passa pela análise do conteúdo do governo representativo no Brasil dos oi tocentos.

Este texto apresenta os primeiros resultados da pesquisa, perseguindo a hi pótese dequea 
monarquia constitucional brasileira preenchia os critérios definidos como essenciais paraa existênciadeumgoverno representativo, tal como eleera entendido no séculoXIX. O quesignifica abrir ca minho para uma nova compreensão do período quenão seja pautada pelaidéia defalseamento das instituições, da importação inadequada demodelos al heios. Ao contrário, trata-se deaveriguar como o desenho institucional previsto na constituição se concretizou, de um lado em harmonia com os modelos quelheserviram deinspi ração, de outro ganhando especificidades ditadas pelo contexto brasileiro.

A historiografia quetem se dedicado ao estudo da história política tem, em geral, uma abordagem pessimista dessa primeira experiêncialiberal. Para partedos historiadores, a iniciativa política estava concentrada nas mãos do imperador, tendo em vista o que ficou conhecido como poder pessoal. Segundo essa visão, o governo representativo erafal seado no Brasil namedi da em que, no exercício do Poder Moderador, o imperador nomeavalivrementeo ministério, semcompromisso com a maioria parlamentar, e, na ausência dela, também como atribui ção do quarto poder, dissolvia a Câmara dos Deputados. Graças ao uso indiscriminado da fraudeel eitoral, seria possível eleger umanova Câmara, composta quaseexclusivamente por deputados pertencentes ao partido no ministérioe, conseqüentemente, submissaaele. Esse mecanismo reti raria qual quer caráter de representação do governo. O governo representativo, assim, não expressaria efetivamentea vontade popular, ea Câmara el etiva deixava deser o espaço deformulação de políticas nacionais (Holanda, 1985; Faoro, 1987; Barman, 1985).

Aceitar a hipótese de que a representação política era uma real idadeno regimemonárquico, tendo em vista os model os vigentes no século XIX, évantajoso na medida em quecol oca novas questões para a pesquisa sobreo período: Qual era sua especificidade, em comparação com seus congêneres europeus enorte-americano? Qual era o peso da Câmara dos Deputados na formulação da política nacional? Essa última pergunta é de especial relevância, dada a magnitude deatribuições da Câmara naquele período e leva à novas perguntas: Quetipo derepresentantes eram selecionados através das el eições? Como isso afetavaa formulação das políticas nacionais? Quem eram os representados? Quais os interesses em jogo? Em quemedida imprensa esociedades organizadas influenciavam as decisões parlamentares? Como os conflitos intra-elitesetraduzi ram em diferentes concepções de representação? Nestetexto, não pretendo responder a todas essas perguntas, mas apontar elementos queajudem aformular as respostas, demodo a não apenas conhecer meIhor o funcionamento do Estado brasileiro no sé culoXIX, mas tambémjogar novas luzes sobreos conflitos intra-elitequedeterminaramadinâmica política.

Para compreender o arranjo institucional brasileiro do século XIX, éútil a aproximação com a ciência política, demodo a analisá-lo deacordo com o modelo de representação política predominantenosoitocentos. Os estudos baseados nacompreensão do governo representativo a partir do seu nascimento, no final do século XVIII, são deespecial interesse. A abordagem histórica permite desvincular representação dedemocraciacontemporânea, sendo estauma variação quesurgiu apenas no séculoXX. Assim, evita-seo risco deanalisar o caso brasi leiro a partir dos padrões de representação que só foram formulados no século seguinte Autores como Bernard Manin, HannaPitkin e Giovani Sartori ressal tam o caráter elitista dos governos representativos organizados na Ingl aterra, França eEstados Unidos, nos quais preval eciam restrições e controles estranhos às democracias modernas. Também não setratava deuma emulação das democracias antigas. Como aponta Bernard Manin, o governo representativo seopunha à democracia ateniense justamente porque selecionava uma eliteque seacreditava capaz de agir de acordo com o interesse nacional, a partir derestrições à participação.

No Brasil, acabou preval ecendo um arranjo peculiar quecombinava características dos modelos inglês e francês. Da França vieram a divisão 
entre cidadãos ativos e passivos, sendo que só os primeiros tinham direito de voto, ea eleição em duas fases, onde os votantes votavam nos eleitores que, por sua vez, votavam nos deputados. Da França e da Ingl aterra veio o voto censitário. Da Françaedalnglaterraveio amonarquiaconstitucional bicameral, comuma câmara eletivatemporária eoutra vitalícia. Também da França veio o modelo demonarquia constitucional no qual a nomeação do ministério pelo rei não precisava corresponder à maioria parlamentar. Dos Estados Unidos veio, a partir da década de 30, a inspiração federativa que tornava os deputados representantes dos interesses provinciais.

Uma vez queas restrições à ci dadania obedeciam ao espírito da época, o el ei torado brasileiro não estava fora dos padrões do período. No que diz respeito ao universo de votantes, conforme apontaJosé Murilo de Carval ho, 13\% da população total (excluindo os escravos) tinham direito de voto, de acordo com o recenseamento de 1872. Emtorno de 1870, na Inglaterra, eram apenas 7\%, na Itália, 2\%, e, na Holanda, 2,5\% (Carvalho, 2001). Mas é preciso tomar com cuidado essas comparações. No Brasil, as el eições eram realizadas em dois graus (votantes escolhiam eleitores que, por sua vez, escol hiam deputados esenadores), seguindo-se o model o adotado na França revolucionária. Como aponta Rosanvallon, o voto deprimei ro grau tem uma natureza distinta do de $2^{\circ}$. grau. Só esseúltimo éefetivamente uma decisão política, enquanto os votantes de $1^{\circ}$. grau exercem apenas um papel delegitimação do processo eleitoral:

as assembléias primárias não fazem mais que designar os el eitores: procedem somente a uma espécie de legitimação original do procedimento representativo. Porém, as verdadeiras el ei ções têm lugar em outra parte, nas assembléias eleitorais, as de segundo grau, que só reúnem a centésima parte dos cidadãos ativos. (Rosanvallon, 1999, p.174).

Não se pode comparar como iguais a participação dos votantes de primeiro grau no Brasil com a partici pação em eleições em países ondeo pleito era direto. São participações de naturezas distintas, uma de legitimação, outra de decisão. Considerando que o número de eleitores de segundo grau no Brasil era muito inferior ao de votantes (cada 40 votantes escol hiam um eleitor, segundo lei aprovada em 1846), provavelmente, se tomarmos apenas os el eitores desegundo grau, o padrão departici pação no Brasil não seapresentariatão superior ao padrão europeu. Detodo modo, dele não se distanciava enão se pode negar que, mesmo com função apenas de legitimação, o voto de primei ro grau era uma forma deincluir setores mais ampl os da população no jogo político.

Na concepção decidadania política prevalecenteno séculoXIX, a exclusão do escravo também se tornava natural. Como aponta José de Alencar, suaincapacidade política derivava, antes detudo, da incapacidadecivil,

... antes de cidadão, o homem é pessoa. Dessa qualidade depende o título de membro da comunhão. Desde, pois, que o indivíduo se acha privado da atividadede seu direito civil, fica virtual mente impedido de exercer o direito político (Alencar, 1997, p.89).

O escravo estava fora da sociedade civil e, portanto, não cabia considerálo como membro da sociedade política. O mesmo problema foi enfrentado nos Estados Unidos. Madison, por exemplo, advogava que o escravo sequer deveria ser contabilizado no cál culo da população que deveria servir de base para estabelecer o número de deputados a que cada estado teria direi to:

os escravos são consi derados propriedades, não pessoas. Devem, portanto, ser incluídos em cálculos de tributação, que se fundam na propriedade, e ser excluídos da representação, que é regulada pel o censo das pessoas (Madison; $\mathrm{Ha}$ milton; Hay, 1993, p.363).

Madison argumentava, nesteponto, contra as pretensões dos grandes proprietários deescravos do sul dos Estados Unidos, que reivindicavam serem os escravos contabilizados para efeito de cál culo da população, de modo a garantirem para seus estados um número mai or de representantes. Acabou preval ecendo, na constituição norte-americana, uma solução intermediária, pelaqual 
oescravo contava comotrêsquintos deumapessoa.

No Brasil, como se sabe, os libertos, pela Constituição de 1824, tinham direito devoto. Uma vez libertado, o ex-escravo adquiria cidadania civil e, conseqüentemente, a possibilidadedecidadania política. É bem verdadequeo liberto pode ria ser apenas votante, mesmo que preenchesse os requisitos para ser el eitor ou candidato, mas isso se justificava pelo fato de que era aceitável que houvesselimites paraque o portador decidadania civil gozasse também de direitos políticos. As mulheres livres, por exemplo, desfrutavam decidadaniacivil, mas não política, uma vez queeram consideradas intel ectualmentelimitadas. O mesmo valia para o li berto, com o seu passado de escravo. O interessanteéque, nesseponto, oliberto eraconsiderado mais apto do quequal quer mulher, mesmo brancaepertencenteà elite, poisnem direito de ser votante ela tinha. A restrição ao liberto, além disso, restringia-se a uma geração, pois o filho do ex-escravotinhaplenosdireitospolíticos, desdeque preenchesseos requisitos constitucionais.

Além da escravidão eas restrições ao direito de voto, a existência do Poder Moderador tem sido argumento para negar o caráter representativo da monarquia brasileira, pois supostamenteconcentrariaa iniciativa políticanas mãos do impera dor, principal mente porque, com sua atribuição de dissolver a Câmara, podia, através da fraude el eitoral, garantir a el eição de deputados fiéis ao mi nistério nomeado por ele. No entanto, o governo representativo era condizente também com a presença do Poder Moderador. A opção pel o quarto poder era uma solução, entreoutras, para uma questão presenteem todas as monarquias constitucionais representativas do século XIX: definir o papel do rei em um governo representativo, dada a natureza hereditária eirresponsável do cargo.

Antes decontinuar o argumento, éútil lembrar queainterferência deum poder sobre o outro éda natureza dos governos representativos. A divisão de poderes, com atribuições defini das pela Constituição, ea independência entre eles não era enão éentendida como ausência de interferência, já quesemprefoi considerada como um elemento necessário para o equilíbrio dos poderes na medida em queéa condição para evitar abusos. Assim, o veto do Executivo à lei promulgada pelo Legislativo éum exemplo deinterferência quegaranteo control enecessário para queo Legislativo não abuse de seu poder. A interferência de um poder sobreoutro era condição para evitar o abuso de poder eno século XIX, eadissolução da câmara eletiva era aceita como forma de interferência legitima. Como aponta Constant,

... el evaram-se reclamações contra o direito de
dissolver as assembléias representativas, direito
atribuído, tanto por nosso ato constitucional
[Constant se refere à Françal como pela consti-
tuiçãa da Inglaterra, ao depositário do poder su-
premo. [...] Nenhuma liberdade, sem dúvida,
pode existir num grande país sem assembléias
fortes, numerosas e independentes; mas essas
assembléias não são isentas de riscos, eno inte-
resse da própria liberdade, cumpre preparar
meios infalíveis para prevenir seus desvios
(Constant, 2005, p.31).

A dissolução era coerente coma representação, uma vez que obrigatoriamente eram convocadas novas eleições para deputados no prazo dealguns meses, demodo quea dissolução significava o funcionamento essencial do governo representativo: no conflito entre Executivo e Legisl ativo, a decisão vol tava às mãos do eleitor. Caberia a ele, através do voto, reconduzir ao parlamento os deputados da legislatura dissol vida, afirmando, assim, sua preferência pela política por eles defendida, ou renovar a Câmara de modo a modificar atendência predominante.

Pode-seargumentar queas eleiçõesnão eram livres no Brasil, devido àfraudeeàviolência. Mas épreciso relativizar o papel da fraudecomo empecilho para a representação. A fraudeel eitoral não era exclusi vidadebrasileira. Era amplamentepraticada nos países que constituíram o berço desse tipo degoverno. Basta lembrar dos burgos podres da Ingl aterra. Como observa Wanderley Guilhermedos Santos,

com o sistema representativo, e com essa institucional ização [da partici pação política via el eição] na Inglaterra, nos Estados Unidos, vieram, como vieram no Brasil no século XIX, [...] a violência, a corrupção endêmica, a fraude, a compra devotos (Santos, 1998). 
A fraudeea violência obviamenteinfluenciavamarepresentação, masépreciso qualificálas para compreender atéqueponto a comprometiam. Dois elementos devem ser considerados para pensar a fraudeno contexto do governo representativo brasileiro. Em primeiro lugar, sua extensão. É difícil, quaseimpossível, medir o quanto afraude contami nava o processo el eitoral. O famoso livro de Belisário Soares de Souza, 0 sistema el eitoral no Império, publicado em 1872, apresenta um quadro no qual a fraude parece ser onipresente. No entanto, épreciso considerar queBelisário escreveu seu livro com um propósito: a defesa de uma noval egislação el eitoral queeliminassea figura dos votantes, com o argumento dequesetratava de homensignorantes e, portanto, sujeitos a todo tipo demanipulação. Sem querer menospre zar a dimensão dafraudenaqueles tempos, élicito supor que ela não tinha magnitude de ordem a comprometer inteiramenteo processo eleitoral , uma vez que este foi um instrumento importante de estabilidadedo regime. A el eição periódica dedeputados era reconhecida pel os atores como forma degarantir queavontadenacional fosseouvidana formulação depolíticas, demodo quefoi possível manter a monarquia constitucional por quaseum século sem grandes abal os institucionais.

Um segundo ponto a considerar em relação à fraude diz respeito aos esforços empreendidos pela eliteimperial no seu combate. Uma profusão deleis debati das e promulgadas tinha como objetivo expresso eliminar as fraudes. Pode-se argumentar queessas tentativas eram meraformalidade. Mas o empenho com que deputados esenadores debatiam a legi sl ação el ei toral denuncia uma real vontade denormatizar as eleições. Além disso, como aponta Bolívar Lamounier, a opção pelo governo representativo era a opção pela criação de um espaço institucional de resolução dos conflitosinter pares, demodo a conferir estabilidadeao regime. Nessesentido, havia “interesseem el eger interlocutores válidos, enão indivíduos desprovidos deliderança, ou meras criações mi nisteriais" (Lamounier, 2005, p.70). Havia, portanto, interesse das próprias elites que os representantes fos- sem assim considerados por aqueles que representavam.

Por outrolado, épreciso avaliar se, no funcionamento efetivo do regime, o quarto poder não acabava sendo um obstáculo à representação, na medida em queresultasseno constrangimento da liberdade de decisão dos deputados. No entanto, a dificuldade do Executivo, em determinados momentos, para conseguir a aprovação deseus projetos na Câmara (como a Lei do Ventre Livre promulgada em 1871 e a dos Sexagenários de 1886) evidencia que, mesmo sob a ameaça de dissolução, os deputados impunham resistência à vontade do imperador. Além disso, o al to custo político dadissolução provavelmentefuncionava como um freio paraqueela não fossepraticada com freqüência. Como nota Sérgio Buarque de Holanda, era um "recurso extremo, quea própria carta de 1824 só admite em casos de exceção [...] e é de supor que seu uso seguido e indiscriminado poderia ameaçar a própria segurança do sistema." (Holanda, 1985, p.11). O autor dá como exemplo a situação de 1862, quando um mi nistério conservador foi derrubado por moção de desconfiança aprovada na Câmara, com apenas um voto dediferença. O ministério liberal que o substituiu teria deenfrentar, assi m, uma câmara dividida, na qual contava com o apoio apenas de cerca de metade dos deputados. A solução seria a dissolução, mas o imperador decidiu não fazê-lo, apesar das dificuldades que o ministério nomeado por ele com certeza enfrentaria, por considerar, conforme confidenciou a interl ocutores, muito al to o custo político da dissolução.

Além disso, a análise das relações entre Legislativo, Executivo e Moderador não indica a submissão do primeiro aos outros dois. As atribuições constitucionais do Legislativo conferiam aos parlamentares grande poder deinfluência no jogo político, desde a elaboração do orçamento anual, quedeterminava os recursos para o funcionamento dos outros poderes, até o controle da constitucional idadeque, no século XIX, concentrou-seno exame das leis provinciais.

As decisões depolíticanacional eramtodas 
tomadas no parlamento: escravidão, organização institucional, forçamilitar, criação detributos, obras públicas, etc. Por setratar demonarquia constitucional, praticamente todas as políticas nacionais assumiam o formato de lei, conferindo à Câmara papel fundamental no jogo político. No que diz respeito, por exemplo, à abolição da escravidão, a opção por uma emancipação gradual ecomindenização, quesematerializou coma Lei do Ventre Livreem 1871, já estava em discussão no Senado desde 1862, quando o conservador Silveira daMota apresentou um projeto nessesentido. $O$ debatese intensificou na Câmara na discussão da respostaà Fala do Trono, em 1867, na qual havia uma rápida menção à necessidade de se resolver o problema do elemento servil. Na discussão da Câmara, a tônica foi a defesa do parlamento como o espaço institucional ondea questão deveriaser resolvida. O deputado Martim Francisco expressou o que muitos deputados insistiram em seus discursos: o bom governo deve ter o voto e a confiança dos parlamentares. Por isso, devesujeitar suas idéias à Câmara, que. por sua vez, deve analisállas de forma desapaixonada. Na visão do parlamentar:

Pronuncia-se a câmara com toda a franqueza em relação à política do ministério, porqueo ministério quer saber se, gozando da confiança dos representantes do país, goza também da confiança do mesmo país, porque é neste augusto recinto quea vontade do país deve manifestar com mais solenidade. ${ }^{1}$

Da mesma forma, Joaquim Nabuco, anos depois, em 1882, insistia quecabia ao parlamento a decisão de como equando abol ir a escravidão. 0 abolicionista repudiava movimentos sociais de contestação da ordem, reconhecendo, nas instituições brasileiras, legitimidadee eficácia para resolver a questão:

A emancipação há de ser feita, entre nós, por uma lei quetenha os requisitos, externos einternos, detodas as outras. É, assim, no parlamento e não em fazendas ou quil ombos do interior, nem nas ruas e praças das cidades, que se há de ganhar, ou perder, a causa da liberdade (Nabuco, 1988, p.40).

${ }^{1}$ Anais da Câmara dos Deputados, 04/07/1867, p. 29.
Esseéum ponto fundamental do debate. A questão da escravidão deveria ser resolvida no interior do arranjo institucional vigente. O quesignificavarespeitar as competências constitucionais. Mais do que resistir a um projeto de libertação gradual dos escravos, em 1867 os deputados al inhavam-sena defesa do parlamento edesuas atribuições contra a ingerência do Executivo.

Para além da formulação das políticas nacionais, a influência decisiva da Câmara na condução do governo estava em quenela era debatido e aprovado o orçamento anual, demodo que os deputados detinham grande poder de interferência nos outros poderes. Não apenas ao aprovar osmeios materiais com queeles poderiamcontar, como também porque cabia à Câmara fiscalizar os demais poderes na execução do orçamento aprovado. Por essa razão, cabia à Câmara também anal isar o balanço geral dareceitaeda despesa real izadas. Como lembraPimentaBueno,

... é demister que os legisladores eo país saibam
se os serviços públ icos foram desempenhados e
as despesas efetuadas ou não na conformidade
do respectivo orçamento [...]. Sem essecontraste,
sem essa prova real, sem contas devidamente
processadas etomadas, os orçamentos são meras
e insufi cientes formal idades. Os mi nistros pre-
terirão ou farão as despesas que quiserem; em-
pregarão, anteci parão rendas, criarão créditos, e
em suma disporão dos recursos do Estado a seu
contento (Bueno, 2002, p.152).

A elaboração do orçamento pela Câmara eletivaéda essência dos governos representativos. Como afirmaAntónio M. Hespanha, o orçamento tinhasignificativacentralidadepolítica, esua

aprovação devia ser, em todos os regimes liberais típicos, uma das atribuições centrais dos parIamentos. Originariamente, esta central idade do orçamento resultava da própria história das revoluções constitucional istas que, quer na América, quer em França, foram desencadeadas por ações anti-fiscai s. A isto acrescia o fato de, sendo a tributação uma ofensa à propriedade e sendo esta última um valor constitucional cardinal do regime, só o parlamento estaria autorizado a limitá-la, mesmo por via fiscal (Hespanha, 2004, p.190).

A extração coercitivadariqueza dos indivíduos pelo Estado só era aceitável se decidida pe- 
los seus representantes. Ao seguir, nesse ponto, o modelo liberal, o regimebrasileiro incorporava um grande poder de interferência da Câmara sobreos demais poderes. O Executivo, por exemplo, não poderia real izar seus programas de governo semo assentimento dos deputados.

O debate parlamentar evidencia tambéma existência da preocupação da el ite política coma qual idade da representação nacional, no sentido detornála eficaz eno sentido de definir seu conteúdo quanto ao grau derepresentatividade. Essa preocupação manifestou-se deforma mais expressa na discussão sobrea legislação el eitoral. Foram basicamentetrês os temas quemobilizaram os parlamentares quanto a esseitem: a fraudeel eitoral, a representação das minorias e o que chamavam de incompatibilidades. Os três temas respondiam a preocupações de fundo, referentes à efetividade do governo representativo: o tipo de representação que deveria preval ecer ea independência entreos poderes. Os três temas freqüentaram os de bates parlamentares desdepelo menos 1828e, entre outras leis, as opções adotadas materializaram-se em quatro mais importantes: a lei de 1846, que afirmava os princípios decidadania consagrados na constituição de 1824, alei de 1855, queadotava o voto distrital e definia a inel egibilidade de detentores de determinados cargos públicos (incompatibilidade), a lei de 1875, queintroduziu o título deel eitor, ealei de 1881, quemodificou os princípios decidadania. Embora cada uma del as tenha secentrado em pontos específicos, as questões mencionadas acima permearam todo o debate. Por exemplo, na discussão da lei promulgada em 1846, cujo foco essencial foi regrar a qualificação dos votantes, o voto distrital foi um tema importante, embora ele só fosse introduzido na lei promulgadaem 1855. O queindica como as reformas el eitorais do império gi raram em torno sempre dos mesmos pontos centrais, sendo que os deputados faziam opções diferentes, em diferentes momentos, variando conforme os percal ços da prática eleitoral. No caso do voto distrital, a sua não adoção foi justificada pelo deputado Andrada Machado, ao apresentar o projeto dereforma eleito- ral quesetornariaalei de1846, da seguinteforma:

Mas se com este expediente seevitava o mal das corvéias, outro mal maior pareceu a comissão dever daí derivar. Ela capacitou-seque semelhante divisão não faria senão enviar ao corpo representativo notabilidades deal deia, em vez deverdadeiras notabilidades provinciais. ${ }^{2}$

O mesmoargumento seria utilizado em 1855 por aqueles que eram contra a Lei dos Círculos, então em discussão. Só que, dessa feita, a maioria dos deputados optou pelo voto distrital .

No Brasil, ao contrário de outros países, a legislação el eitoral do império caminhou no sentido de ampliar as restrições e não o el eitorado. A lei de 1846 indexou em prata os val ores exigidos para votar eser eleito. A lei de 1875 tornou mais rigoroso o processo dequal ificação dos eleitores, $\mathrm{e}$ a lei de 1881 eliminou a eleição em duas fases, excluindo os votantes, eintroduziu a exigência de ser alfabetizado.

Na medida em que, no séculoXIX, a qualidade da representação era consi derada resultado da qualidade do eleitor, os políticos brasileiros apostaram na gradativa diminuição do el ei torado como forma decombater a fraude. Ume eitor analfabeto e, portanto, mal informado epobreeramais vulnerável às artimanhas daquel es que procuravam manipular as eleições. Quando, em 1846, o deputado Andrada Machado apresentou o projeto de reforma el eitoral elaborado pela comissão da Câmara eque previaa indexação do censo exigido em prata, afirmava, referindo-seà fraude:

... corrigir as faltas do governo democrático, bases das eleições populares, é de mais importância do que estender a esfera a queeste governo se pode aplicar. Uma representação apresenta ao poder das multidões um contrapeso na influência das outras classes: el a substitui legisladores hábeis a outros inteiramente incapazes de qualquer função legislativa; e continua a confiança uma vez depositada por todo o tempo suficiente para salvar a legislatura das elusões e frenezi temporário do povo. ${ }^{3}$

2 Anais da Câmara dos Deputados, sessão de 16/8/1839, p.
636 .
${ }^{3}$ Anais da Câmara dos Deputados, sessão de 16/8/1839, p. 636. 
No queserefereàsincompatibilidades, pre servar aindependência entreos poderesera a questão central. A Câmara, como instância el etiva que conferiarepresentação ao regi meatravés da el eição dos seus membros, deveria ser protegi da da interferência de integrantes de outros poderes que porventura seel egessem deputados. Assim, a partir de 1855, uma série de leis foi promulgada declarando impedidos desecandidatar aqueles que tivessem cargos importantes no Judiciário e no Executivo.

Por fim, a representação das minorias foi fonte de intenso debate, acompanhando preocupações quenorteavamtambém os legisladoreseuropeus e norte-americanos. Como o sistema proporcional ainda não era usual na Europa, tendo sido introduzido sóno final do séculoXIX, a preocupação em garantir a eleição das minorias tinha deser resolvida dentro do sistema majoritário. Em 1855, no debate queresultou na promul gação da Lei dos Círculos, os parlamentares optaram, não sem muita discussão, pela adoção do voto distrital emsubstituição ao quechamavam devoto provincial, consagrado na Constituição de 1824. No entanto, o voto provincial também era distrital, já quecada província el egia um número fixo dedeputados e cada eleitor votava em tantos nomes quantos deputados compunham a bancada desua província, sempre pelo sistema majoritário. No esforço degarantir a representação minoritáriasem voto proporcional, a proposta era que o voto fosse por distritos pequenos, ao invés do grandedistrito provincial.

Aquelesqueadefendiamconsideravamessa uma formamais eficientepara garantir a el eição de minoriasno sistema majoritário, uma vez quebastaria ter poder local para ser el eito, enquanto uma circunscrição ampla, como a província, favoreceriao candidato mel hor articulado politicamentee, assim, tornaria quase impossível a eleição decandidatos degrupos minoritários.

No Brasil, aqueles quedefendiama el eição dos mel hores, mais sábios emais ilustrados como única forma de o parlamento formular de modo competente a vontade nacional eram a favor do distrito grande, ou seja, do voto provincial . Aqueles queestavam preocupados coma representação da diversidade batiam-se pel o distrito pequeno.

Na concepção de representação do século XIX, cabia aos representantes, ao mesmo tempo, defender os interesses dos seus el eitores e aquilo queconsideravam constituir os interesses detodaa nação. Muitas vezes, haviacontradição entreos dois campos, sendo que, no Brasil, a defesa dosinteresses dos eleitores se confundia com a defesa dos interesses provinciais que, assim, eram às vezes vistos como em oposição ao interessenacional.

As bancadas tendiam a defender os interesses da provínciaquerepresentavamquando o tema Ihes dizia respeito diretamente. Para que o novo arranjo institucional fosse fiador da uni dade, era preciso que as elites provinciais reconhecessem, nas suas bancadas, um efetivo meio de defesa de seus interesses no interior do Estado (mesmo que nem sempreconseguissem aprovar medidas condizentes com suas demandas), o queseevidencia no fato de que o número de deputados de cada província se tornou a medida do seu grau de influência na política nacional. Uma representação enviada pelaAssembléia Legislativa deSão Paulo ao governocentral, em 1841, refleteclaramenteessa concepção, quando, ao protestar contra os rigores do recrutamento forçado que sofria a população paulista, propõeque

... o número de recrutas exigidos para a formação do exército do Império seja repartido pelas províncias na proporção do número dos deputados que cada uma delas envia à Assembléia Geral. Sendo um princípio inegável de justiça que os ônus devem ser proporcionais às vantagens que se col hem do contrato social, e estas vantagens rel ativas à parte que cada uma das províncias toma na decisão dos negócios gerais, o que fica evidente pelo número de deputados que nomeia, parece quesemel hante regra deveser adotada como a mais justa. ${ }^{4}$

A representação paul ista reconhecia, desse modo, queo grau deinfluência das provínciasnas decisões do governo central era determinada pelo

${ }^{4}$ Anais da Assembléia Legislativa Provincial de São Paulo. $1840 / 1841$. 
número de deputados queel egia. A representação naCâmara tinha, assim, conteúdo territorial .

Essa concepção derepresentação estevepresente na discussão do voto distrital em 1855 . Os defensores do voto distrital (distrito pequeno) argumentavam queo distrito grandefavoreciaa existência de bancadas provinciais coesas. O quesignificava queas províncias com maior número de deputados imporiam seus interesses aos demais, enquanto o voto por distrito pequeno resultaria em bancadas fragmentadas, favorecendo a negociação ao invés da imposi ção dos interesses de um setor apenas. Pimenta Bueno fazia a defesa do voto distrital alegando queas grandesprovínciastinham força, através do parlamento, de fazer val er seus interesses frente o governo central, em detrimento das pequenas províncias, combancadas menores:

O que vemos porém no Brasil? Vemos a par de pequenas províncias outras consideráveis, que relativamente são grandes Estados, Estados preponderantes, quetêm interesses distintos eopostos, como que nacional idades diversas, com forças desproporcionadas e capazes de entrar em luta com o governo central e por em dúvida a indivisibilidade do império. [...] Esteénosso estado, inconvenientee perigoso: ecomo sobreele influi o atual sistema el eitoral? Tende a corrigir e neutralizar esses inconvenientes e perigos ou a reforçá-los? Enquanto as el eições conti nuarema ser feitas por províncias, como atual mentesão, a resposta não podeser duvidosa. ${ }^{5}$

Ao apontar o papel das bancadas parlamentares na representação dos interesses provinciais frenteo governo central, Pimenta Bueno associava a discussão do voto distrital ao tamanho da bancada a que cada província tinha direito. Dessa forma, sua argumentação continuava no sentido de salientar o que considerava uma injusta desproporcionalidade:

A província de Minas tem na câmara dos deputados 20 representantes e no senado 10, tem pois uma representação igual a de 10 províncias do Brasil, tanto em uma como noutra câmara, pois que na câmara dos deputados a província do Amazonas tem 1, Espírito Santo 1, Paraná 1, Santa Catarina 1, Goiás 2, Mato Grosso 2, Piauí 2, Sergipe2, Pará 3, Alagoas 5, ao todo 10 províncias com 20 deputados. (...) Ora, haverá, porventura,

${ }^{5}$ Anais do Senado, sessão de 18 de julho de 1855. proporção al guma razoável quando uma só província influi no parlamento brasileiro tanto como dez outras?Não direi mesmo tanto, esim mais do quedez outras, por isso que os vinterepresentantes destas não se ligam entre si, têm interesses divergentes, não têm a força de seu número. ${ }^{6}$

A representação dos el eitores convivia, no Brasil, com umarepresentação decaráter nacional. Os deputados eram representantes da nação, seguindo, aqui, a concepção burkeana: cabia a eles identificar o bem comum elegislar deacordo com ele. Claro está queo quecada qual consideravaser obem comum variava deacordo com diversosquesitos: extração social, origem provincial, filiação partidária, etc., e, por essa razão, o debate parlamentar assumiapapel crucial noenfrentamentoentre posições ena formulação da política nacional. Em conseqüência, era preocupação central agarantiade eleição derepresentantes portadores de virtudeque os habilitasse a atuar de acordo com o interesse nacional, definido por eles próprios.

Dessatensão resultavaqueo mesmo deputado, em determinado momento, pautava sua atuação tendo em vista os interesses desua provínciae, em outros, aquil o que considerava ser o interesse nacional. Obviamente, essaúltima posição era, em geral, tomada quando interesses específicos desua províncianão estavamemjogo. A tensão ocorriana medida em queessa oscilação gerava expectativas opostas no interior do debate Por exemplo, em 1850, ao exercer sua atribuição de controle da constitucionalidade, os deputadosenfrentaramuma dura discussão sobrea constitucionalidadedeuma lei promulgada pela Assembléia Legislativa de Pernambuco. Na discussão, o conservador João Manuel Pereira daSilva, deputado pelo Rio deJaneiro, afirmava que:

A susceti bilidade dos honrados membros deputados por Pernambuco foi tal queatéseacusou o meu honrado amigo, deputado pela Bahia e autor do projeto, de se deixar eivar do espírito do provincialismo na questão de que se trata. Se pode haver acusação de espírito de provincialismo a este respeito não cabe certamente àqueles que votam contra o adiamento e em favor do projeto, pertencentes como são a di-

${ }^{6}$ Ibidem idem. 
versas províncias, mas sim aos ilustres deputados por Pernambuco, que reconhecendo que são ilegais essas leis de sua província, entretanto querem que elas permaneçam. ${ }^{7}$

A acusação de provincial ismo, lançada de partea parte, funcionava como desqual ificação da posição do oponente, mas fazia sentido justamenteporqueas bancadas mobilizavam-separa defender os interesses desuas províncias, demodo que aCâmara dos Deputados setornavaa instância no interior da qual as elites regionais podiam intervir na política nacional. Ao mesmo tempo, contudo, estavam compenetrados desua condição derepresentantes da nação, situação bem sintetizada por D. Manoel deAssis Mascarenhas, deputado pelo Rio deJaneiro:

É verdade, senhores, quenós somos representantes da nação, mas também é verdade que devemos mais particularmente advogar os interesses de nossas províncias porque estamos deordinário mais habilitados para conhecermos dos interesses delas. Portanto, não se deve censurar que um deputado da Bahia, por exemplo, ou do Rio de Janeiro, proponha a revogação de um ato da assembléia provincial de Pernambuco que ele entende que vai de encontro não só à Constituição, mas também aos interesses da província que o honrou com os seus votos parater assento nesta casa. $^{8}$

A Câmara dos Deputados, como órgão de representação por excelência, era vista como o instrumento pel o qual o povo participava do governo do país. Seus representantes lá estavam para defender seus interesses. Mas uma das tensões básicas dos governos representativos está no fato de que o representanteétambém governo e, porisso, tem com o representado uma relação de imposição. O representante é, dessa forma, sempre um agenteda local idade que o el egeu, como também um governante da nação, "his duty is to pursue both local and national interest, the one because Heis a representative, the other because his job as representative is governing the nation" (Pitikin, 1967, p.218). Assim, a Câmara de Deputados era, ao mesmo tempo, o espaço de representação dos

${ }^{7}$ Anais da Câmara dos Deputados, sessão 23/5/1850.

${ }^{8}$ Ibidem, idem. interesses dos representados eo espaço deformulação de políticas nacionais. Sua função precípua era formular as leis às quais todos, do rei ao mais humildedos brasileiros, teriam desesubmeter.

O Poder Moderador, a fraude eleitoral, a escravidão eo voto censitário não eram incompatíveis com o model o de representação política do século XIX. Ao contrário, como se procurou demonstrar, com exceção do Poder Moderador, estavam presentes nas experiências européias degoverno representativo (fraude e voto censitário) e norte-americanas (fraudee escravidão). E estavam presentes porquenão afrontavam a forma pelaqual se pensava, então, a ci dadania ea representação. O Poder Moderador, apesar de restrito às experiências brasileira eportuguesa, também não fal seava a monarquia constitucional representativa, tal qual o modelo preval ecenteno período.

No Brasil, o desafio deconstruir um governo representativo centrou-se na forma de organizar as instituições, demodo a adaptar os modelos conhecidos à real idadeespecífica do país. Os políticos brasil eiros acalentaram projetos distintos, tendo em vista concepções diversas de representação ediferentes interesses projetados na ordem institucional . A opção por um governo representativo permitiu trazer para o interior do Estado as disputas deinteresses entreos diversos setores da elite.

No processo deconstrução do Estado brasileiro, aCâmara dos Deputados viabilizou a relação delegitimidadeentrepopulaçãoegoverno, por ser eletiva, etornou-seespaço denegociação deconflitos através daformulação institucional depolíticas. Cumpriu, assim, o papel quesuas congênerescumpriramna Europa eEstados Unidos.

(Recebido para publicação em janeiro de 2008) (Aceito em março de 2008)

\section{REFERÊNCIAS}

BARMAN, Roderick. Brazil. The forging of a nation (17981852). Stanford: Stanford University Press, 1988

BUENO, José Antônio Pimenta. Direito público brasileiro 
e análise da constituição do Império. In: KUGELMAS, MANIN, Bernard. Los principios del gobierno representaEduardo (Org.) Marquếs de São Vicente. São Paulo: Edi- tivo. Madrid: Alianza Editorial, 1998.

tora 34, 2002.

NABUCO, Joaquim. 0 abolicionismo. 5.ed. Petrópolis:

CARVALHO, José Murilo de. Cidadania no Brasil. Rio de Janeiro: Civilização Brasileira, 2001.

CONSTANT, Benjamin. Escritos de política. São Paulo: Martins Fontes, 2005.

Vozes, 1988.

NICOLAU, Jairo Marconi. As distorções nas representações dos estados na Câmara dos Deputados brasileira. Dados: revista de ciências sociais, Rio de Janeiro, IUPERJ, v.40, n.3, 1997.

DOLHNIKOFF, Miriam. O pacto imperial: origens do federalismo no Brasil. São Paulo: Globo, 2004.

FAORO, Raymundo. Os donos do poder. 7.ed. Rio de Janeiro: Globo, 1987.

NORTON, Philip. Representation of interests: the case of the British House of Commons. COPELAND, Gary W.

PATTERSON, Samuel C. (Ed.) Parliaments in the modern world. 4.ed. Michigan: University of Michigan, 1997.

HESPANHA, Antonio Manuel. Guiando a mão invisível. Direitos, Estado e lei no liberalismo monárquico português. Coimbra: Livraria Almedina, 2004

HOLANDA, Sérgio Buarque de. Do Império à República. História geral da civilização brasileira. 4.ed. São Paulo: Difel, 1985. T.2, v.5.

LAMOUNIER, Bolívar. Da Independência a Lula. São PauIo: Augurium Editora, 2005

PITKIN, Hanna. The concept of representation. Los Angeles: University of California Press, 1967.

ROSANVALLON, Pierre. La consagración del ciudadano. San Juan: Instituto Mora, 1999.

SANTOS, Wanderley Guilherme dos. A anomalia democrática: adol escência e romantismo na história política Revista Brasileira de Ciências Sociais, São Paulo, Anpocs, v.13, n.36, 1998. [online].

MADISON, James; HAMILTON, Alexander; JAY, John. Os artigos federalistas. Rio de Janeiro: Nova Fronteira, 1993.

SARTORI, Giovanni. A teoria da representação no Estado representativo moderno. Bel o Horizonte: Faculdade de Direito da UFMG, 1962. 
IMPÉRIO DE GOVERNO REPRESENTATIVO: uma releitura

Miriam Dolhnikoff

Este artigo analisa o governo representativo no Brasil, no decorrer do sémonarquia constitucional brasileira não se afastou dos modelos de representa- stand apart of th ção política então vigentes na Europa. representation then effective in Europe. Com esse objetivo, o artigo examina o With that aim, the paper examines the Poder Moderador, os critérios de cidada- Poder Moderador, the citizenship criteria nia e a legislação eleitoral.

PALAVRAS-CHAVE: governo representativo, KEYwORDS: representative government, monarquia constitucional, eleições, ci- constitutional monarchy, elections, dadania, poder moderador. xinent in Brazil, in the closing of the XIX century, so as to show that the and the electoral legislation.

EMPIRE OF REPRESENTATIVE

\section{Miriam Dolhnikoff}

This paper analyzes the representative citizenship, poder moderator.
L'EMPIRE DU GOUVERNEMENT REPRÉSENTATIF: une nouvelle lecture

\section{Miriam Dolhnikoff}

Cet article fait une analyse du gouvernement représentatif au Brésil, au XIXe siecle. Il essaie de montre combien la monarchie constitutionnelle brésilienne ne s'est guère éloignée des modèles de représentation politique en vigueur, à l'époque, en Europe. C'est ans ce but qu'on y étudie le Pouvoir Modérateur, les critères de citoyenneté et la législation électorale.

Mots-CLÉs: gouvernement représentatif monarchie constitutionnelle, élections, citoyenneté, pouvoir modérateur. 